\title{
Interventricular septal thickness as a diagnostic marker of fetal macrosomia
}

\author{
Authors: Szmyd B ${ }^{1,2}$, Karuga FF${ }^{2}$, Biedrzycka M², Rogut $\mathrm{M}^{2}$, Respondek-Liberska M, MD, PhD ${ }^{3,4}$ \\ (mentor) \\ ${ }^{1}$ Department of Pediatrics, Oncology and Hematology, Medical University of Lodz, Poland \\ ${ }^{2}$ Student's Scientific Association Prenatal Cardiology, Medical University of Lodz, Poland \\ ${ }^{3}$ Department for Diagnoses and Prevention, Medical University of Lodz, Lodz, Poland \\ ${ }^{4}$ Department of Prenatal Cardiology Polish Mother's Memorial Hospital, Lodz, Poland \\ DOI: https://doi.org/10.26800/LV-142-supp5-51
}

\section{Introduction:}

Serious complications in both mother and child arising as a result of fetal macrosomia indicate the need for early diagnosis and prevention. Unfortunately, current predictors such as fetal biometry, fundal height and amniotic fluid index appear to be insufficient.

\section{Aim of the study:}

Therefore, we decided to assess the predictive potential of interventricular septal thickness (IVST) as $\begin{array}{lllll}\text { measured } \quad \text { in } & \geq 33 & \text { weeks } & \text { of }\end{array}$

\section{Material and methods:}

299 patients met the inclusion criteria: $\geq 33$ weeks of gestation and a complete medical history including all necessary measurements, namely IVST obtained by M-mode echocardiography, fetal biometry information and birth weight. Statistica 13.1 PL software was used to generate the receiver operating curve.

\section{Results:}

$46.43 \%$ of macrosomia cases were predicted based on fetal biometry abnormalities. IVST is a promising macrosomia predictor, with an area under the curve of $0.644(0.525-0.762 ; p=0.0177)$. Using the Youden index method, a cut-off point of $4.7 \mathrm{~mm}$ was selected as the most optimal threshold for diagnosis, detecting up to $71.43 \%$ of cases.

\section{Conclusion:}

IVST at $\geq 4.7 \mathrm{~mm}$ appears to have a higher sensitivity and NPV than ultrasound, which was reported both here and elsewhere

Key words: Fetal Macrosomia, Macrosomia, Interventricular Septal Thickness, Prenatal Cardiology 